\title{
La variación en la cortesía: estudio pragmalingüístico del fenómeno en el español castellano
}

\author{
Alejandro Carmona SANDOVal \\ Universidad Internacional de Valencia \\ alejandro.carmona@campusviu.es \\ NURIA CABEZAS GAY \\ Universidad Internacional de Valencia \\ nuria.cabezas@campusviu.es \\ ZAKIA AIT SAADI \\ Universidad Internacional de Valencia \\ zakia.ait@campusviu.es
}

Resumen: En este trabajo, se presentan los resultados de un análisis de las estrategias de cortesía empleadas por nativos españoles en su lengua L1 (español castellano), la expresión de diferentes actos de habla: la petición, la negación, la instrucción, la queja y el mandato. La actividad se ha desarrollado mediante un TCD. Se pidió a los encuestados que rellenaran diferentes enunciados a partir de un cortometraje animado mudo. A cada enunciado se solicitaba al informante que asociara el grado de cordialidad de cada escena. Una vez recopilados los datos, se analizaron las diferencias en la formulación de los actos de habla junto con el grado de cordialidad asignado. Los resultados, aplicables en clase de ELE, muestran una relación entre el grado de cordialidad identificado y las estrategias discursivas empleadas, y confirma la adopción de estrategias y procedimientos expresivos ya identificados por la literatura científica.

Palabras clave: pragmática, cortesía, TCD, ELE.

\section{Variation in politeness: a pragma-linguistic study of the phenomenon in Castilian}

Abstract: This article presents the results from an analysis of the politeness strategies used by Spanish native speakers in their L1 (Castilian) to express different speech acts: request, denial, instruction, complaint and mandate. The analysis was carried out using a Discourse Completion Test (DCT). Respondents were asked to fill in different sentences from a silent animated short film. Respondents were also asked to associate the degree of cordiality of each scene to the sentences they provided. Once the data was collected, the differences in the formulation of the speech acts were analysed together with the assigned degree of politeness. The results, which may also apply to SFL teaching, show a relationship between the identified degree of politeness and the discursive strategies used, and it also confirms the adoption of expressive strategies and procedures already identified by the scientific literature.

Key words: pragmatics, politeness, DCT, SFL. 


\section{Introducción}

La necesidad del estudio de la pragmática como elemento fundamental de la lengua queda evidenciada por la convicción generalizada de que cualquier uso de nuestros códigos lingüísticos tiene un componente social, en tanto que regulado por normas establecidas. Al comunicarnos con alguien o con un grupo de personas, interactuamos y establecemos unos lazos con nuestros interlocutores. Nos expresamos atendiendo a nuestro estado de ánimo y nuestros mensajes quedan sujetos a nuestras motivaciones y a las intenciones que deseamos materializar en cada momento.

Al admitir el carácter funcional de la actividad comunicativa, el análisis de la lengua no puede limitarse a su carácter sistémico, en tanto en cuanto se hace necesaria la adaptación de una unidad más funcional, como es el acto de habla:

La razón para concentrase en el estudio de los actos de habla es, simplemente esta: toda comunicación lingüística incluye actos lingüísticos. La unidad de la comunicación lingüística no es, como se ha supuesto generalmente, el símbolo, palabra, oración, ni tan siquiera la ejemplificación del símbolo, palabra u oración, sino más bien la producción o emisión del símbolo, palabra u oración al realizar el acto de habla. (Searle, 1980/2017: 29)

Siendo el acto de habla una unidad clave para el estudio y el entendimiento de la pragmática, surge la necesidad de establecer relaciones válidas entre la producción y la interpretación de expresiones comunicativas, relaciones, a su vez, determinadas por el contexto ${ }^{1}$. Bravo (2004: 27) delimita ese mismo concepto como aquel que abarca todo lo «extralingüístico»y sociocultural de un mensaje, es decir «desde acciones físicas realizadas en el interior de la misma situación comunicativa hasta elementos externos a la propia situación, como las características sociales de los/las participantes, sus creencias, actitudes y valores» (Bravo, 2004: 27).

Para que la comunicación pueda ser exitosa, resulta, por tanto, imprescindible que haya algún un punto de intersección, un «lugar cognoscitivo» donde la información pragmática entre los interlocutores pueda ser compartida (Escandell Vidal, 2013: 35). Ese «lugar de encuentro» constituye el núcleo sobre el cual la información que emana de la interacción podrá asentarse tanto por parte del emisor como por parte del receptor. En este sentido, el componente sociocultural de la actividad comunicativa no implica únicamente la existencia de información fáctica, sino también de costumbres, valores y concepciones del mundo que nos rodea y, finalmente, las normas mismas de uso e interpretación de la lengua.

En este trabajo, proponemos ahondar en el estudio de la lengua desde un enfoque pragmalingüístico que tenga en cuenta los valores socioculturales que inciden en la generación de determinados actos de habla y en la adopción de estrategias y procedimientos de cortesía. El análisis de los datos recabados (véase Anexo I) podrá ser aprovechado para la enseñanza del español como lengua extranjera, con el objeto de que los alumnos puedan minimizar el proceso de interferencia entre la L1 y la L2 (Galindo Merino, 2005).

\footnotetext{
${ }^{1}$ La intención de Searle no era asociar el acto de habla al uso del lenguaje en situaciones comunicativas concretas (parole), sino con la langue (Haverkate 2004: 57): «[...] un estudio adecuado de los actos de habla es un estudio de la langue» (Searle 1980/2017: 31).
} 


\section{La cortesía}

La cortesía constituye uno de los ámbitos de estudio más prolíficos del área de la pragmática. Ya desde la década de los setenta, autores como Lakoff (1973), Grice (1975) o Leech (1983) trataron de desbrozar el camino hacia el estudio del proceso de comunicación proveyendo máximas o reglas en las que la cortesía aparece como un elemento facilitador de la interacción humana, facilitando así su entendimiento y maximizando su eficacia.

Según Escandell Vidal (2013: 142, 144), la cortesía puede entenderse de dos maneras: como normal social, es decir, como el «conjunto de normas sociales establecidas por cada sociedad, que regulan el comportamiento adecuado de sus miembros, prohibiendo algunas formas de conducta y favoreciendo otras», o como estrategia conversacional, es decir, «una estrategia para poder mantener las buenas relaciones» con el fin de mitigar conflictos interpersonales. Hoy en día, los estudios lingüísticos proponen un desarrollo del concepto de cortesía desde enfoques comunicativos y socioculturales diversos. Los numerosos estudios en la materia parecen concordar sobre el hecho de que la cortesía existe de manera universal, si bien los modelos panculturales desarrollados en sus inicios fueron poco a poco dando paso a materializaciones socioculturales propias (Haverkate, 1994, Bravo, 2004, Kerbrat-Orecchioni, 2004).

El modelo a día de hoy mayormente utilizado para identificar y analizar la casuística en materia de cortesía es el aportado por Brown y Levinson ([1978] 1987). Su propuesta parte de la noción de imagen social (face), tomada de Erving Goffman (1967) entendida como la autoimagen que toda persona desea para sí misma y que desea mantener en sus contactos con otras personas. En este sentido, la imagen social no se mantiene constante, sino que varía según el momento: puede perderse, valorizarse o mantenerse. De la imagen social, según Brown y Levinson, derivan la «imagen positiva» y la «imagen negativa», dos conceptos complementarios de la identidad social: mientras que el primero se refiere al deseo de mantener el espacio propio libre de intromisiones, el segundo se focaliza en el deseo de ser apreciado socialmente. Ambos conceptos (imagen positiva y negativa) han sido criticados por numerosos autores, ya que, tal como hemos indicado anteriormente, a pesar de la pretensión universalista del modelo, resulta difícil observar ese mecanismo de comportamiento para otras culturas. Los conceptos de «imagen de autonomía» e «imagen de afiliación» resultan muy útiles para solventar parte de esta problemática teórica, tomando en cuenta los diferentes contextos socioculturales en los que la comunicación tiene lugar. Tal como afirma Bravo (1999: 160), para la necesidad de autonomía, «el individuo se percibe a sí mismo y es percibido por los demás como diferente del grupo», mientras que, para la necesidad de afiliación, el individuo es percibido «como parte del mismo». La materialización de cada necesidad se hará teniendo en cuenta el contexto sociocultural de los hablantes, es decir, un «contexto específico que abarca comportamientos, actitudes y valores que son conocidos, aceptados y practicados en una comunidad de hablantes» (Hernández Flores, 2004: 96-7).

A pesar de esas críticas (entre otras), la originalidad del modelo de Brown y Levinson, tal como señala Kerbrat-Orecchioni (2004: 42) radica en haber sido capaces de cruzar las aportaciones provistas del concepto de «acto de habla» de Searle con el trabajo propio de imagen provisto por Goffman. A partir de este último, Brown y Levinson también tratan de explicar cómo a través de la cortesía las personas intentan satisfacer sus deseos de imagen. El proceso toma como base el concepto de «face work» (trabajo de imagen), también propuesto por Goffman. Siguiendo este enfoque, todo interlocutor tratará de salvaguardar, mediante diferentes estrategias comunicativas, su imagen social. Es así como determinados actos de 
habla pueden llegar a ser intrínsecamente amenazantes para la imagen social (Face Threatening Acts, FTA). Para mitigar el riesgo, los interlocutores recurren a distintos tipos de estrategias de cortesía, entre las cuales se encuentran el uso de mitigadores o atenuantes, elementos utilizados para poder suavizar la interpretación de aquellos efectos más o menos hirientes de nuestras palabras. Briz los define así:

\begin{abstract}
Categoría pragmalingüística en tanto forma asociada a una actividad estratégica, es una operación lingüística de minimización de lo dicho y del punto de vista, que afecta, así pues, al valor intencional, a la fuerza ilocutiva, es decir, una operación vinculada a la actividad argumentativa y de "negociación" del acuerdo, que es el fin último de toda conversación. (Briz, 2004: 68)
\end{abstract}

Sin embargo, los elementos de cortesía pueden aparecer sin que en principio se prevea una situación amenazante, haciendo de la cortesía un medio no solo para mitigar las amenazas a la imagen, sino también para realzarla (Haverkate, 1994, Bravo, 2000, Hernández Flores, 2004, Albelda 2004). Es así como los actos de refuerzo de la imagen (Face Flattering Acts) (Kerbrat-Orecchioni, 1996, 2004) pueden aparecer con el objeto de halagar o ensalzar directamente la imagen $\mathrm{u}$ otro objeto íntimamente relacionado con la imagen del oyente. Algunos ejemplos de estos actos pueden ser el cumplido, la alabanza o el elogio.

Como parte del estudio de la imagen, numerosos autores han propuesto, a través de estudios inductivos o deductivos, dar cuenta de las estrategias y procedimientos atenuadores más utilizados, en nuestro caso, en español peninsular. Entre ellos, Kerbrat-Orecchioni (2004: 42) propone el siguiente listado: los actos de habla indirectos, los desactualizadores modales, temporales o personales; los procedimientos retóricos (lítote o eufemismo); las fórmulas de cortesía de antiguo repertorio; los enunciados preliminares; los procedimientos reparadores, desarmadores, aduladores, modalizadores o minimizadores. Por su parte, Briz (1996/2017) incorpora una lista abierta de elementos que, de alguna manera, inciden positiva o negativamente en esa negociación interpersonal, a modo de atenuante o intensificador: los conectores pragmáticos (es que, pero, con que, etc.); los marcadores de contacto (¿no?, ¿sabes?, etc.); los intensificadores/atenuantes morfológicos y sintácticos, léxico-semánticos; los lexemas marcados ya semánticamente con un rasgo intensificador o atenuador; los deícticos; el uso de tiempos verbales concretos; la preferencia por determinadas unidades léxicas (repeticiones, léxico argótico, etc.); etc.

En esta investigación, se ha realizado un primer análisis de las estrategias empleadas por un grupo de hablantes nativos de español peninsular vinculados a una única cultura de acercamiento, la española. Nos interesa analizar si las características expuestas aparecen plasmadas en nuestros resultados, para la creación de diferentes actos de habla considerados como amenazantes: la petición, la negación, la amenaza y la instrucción.

\title{
3. La cortesía y la enseñanza de la lengua extranjera
}

Según Gutiérrez Ordóñez (2015: 68), «aprender una lengua no consiste únicamente en asimilar el aparato formal (su gramática), sino también las reglas pragmáticas de adecuación a las circunstancias». En el capítulo anterior, hemos insistido en la necesidad de considerar la cortesía como un fenómeno de negociación de imagen universal, cuya materialización, sin embargo, depende de factores socioculturales propios. Para el aprendizaje de una lengua extranjera, resulta importante mantener una postura muy activa sobre el fenómeno de «transferencia», que deriva de la tendencia de los alumnos a trasladar las normas 
sociolingüísticas de su primera lengua hacia la lengua de aprendizaje (Galindo Merino, 2005). El proceso, trasladado al fenómeno de la cortesía, repercute directamente sobre la enseñanza y aprendizaje de segundas lenguas en tanto que las normas pragmáticas pueden ser diferentes de una lengua y cultura a otra. Por ello, tal como indica Peláez Torres:

[...] poseer una competencia pragmática suficiente en la L2 es esencial para el alumno, no solo por estas diferencias socioculturales sino también porque, en contextos de comunicación intercultural, no ser suficientemente competente puede acarrear consecuencias negativas para el estudiante. (Peláez Torres, 2017: 473)

La misma autora apunta a errores de incomprensión debidos a la falta de mecanismos necesarios para emitir o interpretar enunciados, o al hecho de disponer de otros que resulten nefastos para que la enunciación se amolde a las reglas sociopragmáticas de los hablantes de la L1.

Las aplicaciones didácticas en clase de L2 para resolver aquellos casos de transferencia pragmática pueden agruparse en dos tipos, si bien parece no existir un consenso sobre la idoneidad de cada uno, que dependerá en gran medida del nivel del alumnado (Galindo Merino, 2005: 294). Es así como determinados lingüistas proponen aplicar ejercicios de pragmática explícitos en clase de L2, acompañados de explicaciones bien en la L1, bien en L2. Otros, en cambio, estiman que la pragmática no debería ser enseñada en el aula, sino a través de elementos audiovisuales auténticos, dando así la posibilidad al alumnado de experimentar el uso real de la lengua, acorde con las normas sociopragmáticas que la definen.

El presente trabajo se sitúa a medio camino entre ambas posturas: se propone un estudio aplicado que dé cuenta de cómo personas nativas provenientes de un contexto sociocultural determinado (cultura española) hacen uso de la lengua (español) para la creación de determinados actos de habla: la petición, la negación, la instrucción, la queja y el mandato. Los datos aportados podrán ser utilizados como material auténtico o analizados entre profesor y alumnos. No obstante, cabe la posibilidad de que los alumnos (estudiantes de español como L2), también, puedan realizar la misma encuesta para, acto seguido, contrastar sus respuestas con las indicadas en este trabajo.

\section{La encuesta}

Por medio de un test de compleción de discurso (TCD) mediante respuesta abierta (Kasper, 2000), se pidió a alumnos de Grado de Traducción e Interpretación que visualizaran un cortometraje animado mudo denominado Monsterbox (disponible en YouTube y otras plataformas en línea de visualización de vídeos). Su creación data de 2012 y fue elaborado por estudiantes de artes gráficas de la Escuela de Arte y Diseño Bellecour. A pesar de su propósito académico, el vídeo ha sido ampliamente difundido por estudiosos y profesionales del área de la psicología y de la pedagogía por su potencial para trabajar elementos como la empatía y la inteligencia emocional. El carácter altamente visual y mudo del cortometraje posibilita que se pueda unir un diálogo a la trama y adaptar así un guion propio en función de la interpretación de cada persona.

El TCD presenta diferencias metodológicas con respecto a otros métodos, por ejemplo, los métodos de recogida de conversaciones naturales o los juegos de rol en los que las respuestas no son estereotipadas sino reales (Cohen, 1998; Muñoz, 2000). No obstante, sí nos permite centrarnos en determinados actos de habla, desarrollar un análisis cerrado del mismo (acto principal y subactos periféricos) y recabar un número importante de respuestas precisas de un 
mismo contexto comunicativo. Por otra parte, también resulta conveniente para la realización de estudios comparativos (variedades diatópicas, estudios interlingüísticos, etc.). Por último, el carácter audiovisual de nuestro test añade un elemento innovador, en tanto en cuanto es el encuestado quien establece el grado de cordialidad de su discurso (sobre una escala de entre 1 y 5), interpretando no solamente las consignas escritas en el mismo test, sino también los elementos visuales que integra el cortometraje (expresiones faciales, elementos cinéticos, colores, música de fondo, etc.).

Nuestro TCD se compone de seis preguntas vinculadas a seis situaciones comunicativas (escenas). Para cada pregunta, se pidió que el alumno rellenara el enunciado que, a su entender, expresaría el personaje. Para garantizar una dispersión en las respuestas, cada pregunta venía acompañada de una descripción y de la intención comunicativa de los actores.

A continuación, se exponen el acto de habla principal vinculado a cada pregunta, la horquilla temporal durante la cual se desarrolla la escena, y la descripción del contexto y la intención comunicativa.

1. PETICIÓN (54" - 59"). [El niño pide una casita de madera para su monstruito]. ¿Cómo lo dirías si fueras el niño?

2. RECHAZO (59" - 1'08"). [El hombre, ante la petición del niño de tener una casita, mira el monstruo y le dice que no puede vendérsela porque debe ser un pájaro como el que ve]. ¿Qué dirías en toda esta sección, si fueras el hombre?

3. MANDATO (1'38" - 1'46"). [El pájaro, con cierto desdén, le espeta al monstruito que se aleje para enseñarle cómo entrar en la casita]. ¿Cómo lo dirías si fueras el pájaro?

4. INSTRUCCIÓN (2'41" - 2'50"). [El hombre, al ver el niño con la regadera, le dice que no la debe utilizar para regar las plantas, sino que debe hacerlo con un pulverizador]. ¿Cómo lo dirías si fueras el hombre?

5. MANDATO (3'46" - 3'57"). [El hombre, al ver que el gran monstruo ha roto la maceta, se enoja y reclama al mismo que tenga cuidado]. ¿Qué dirías si estuvieras en su lugar?

6. QUEJA / MANDATO (3'46" - 3'57"). [El hombre, al ver que el gran monstruo ha roto la maceta, se enoja y reclama al mismo que tenga cuidado]. ¿Qué dirías si estuvieras en su lugar?

8. Escena 1 (54" - 59") [explicación: el niño pide una casita de madera para su monstruito]. ¿Cómo lo dirias si fueras el niño?

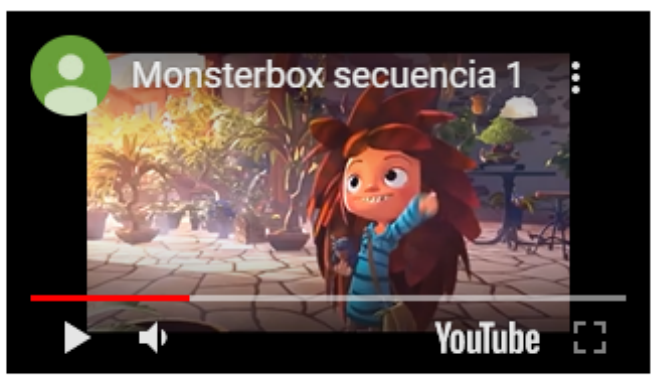

Imagen 1. Muestra de la encuesta. Pregunta (escena) 1. 
De manera complementaria, se pidió a los encuestados que evaluaran el grado de cordialidad ligado a cada situación comunicativa (escala Likert, de 1 a 5). Este segundo elemento resulta de especial interés para nuestro estudio, ya que permite relacionar las estrategias pragmalingüísticas de cada encuestado con el grado de cordialidad interpretado de manera (inter)subjetiva.

La muestra objeto de esta investigación la constituyen un total de 31 personas, con edades entre los 18 y 60 años. El 90,32\% (28) son mujeres, frente al 9,68\% (3) compuesto por hombres. Los encuestados son todos estudiantes de Traducción e Interpretación (formación oficial a distancia) y nativos españoles, residentes mayormente en España, para 25 de ellos.

La encuesta se realizó mediante la herramienta Formularios Google. Se envió a todos los alumnos del Grado en Traducción e Interpretación, por correo electrónico. Desde el día de su recepción, los alumnos dispusieron de 15 días para rellenarla. El número de respuestas recibidas ascendió a $31(\mathrm{~N}=120)$, lo que representa un $26 \%$ sobre la población ya determinada, atendiendo a un muestreo probabilístico (Alvira Martín, 2011). Los resultados de la encuesta están disponibles al final del trabajo (Anexo I).

\section{Resultados}

Para comenzar, creemos importante resaltar la heterogeneidad recibida en cuanto a la interpretación del grado de cordialidad de cada escena. Frente a los TCD realizados por medios tradicionales (no audiovisuales), el soporte sobre el cual la encuesta se ha realizado permite hacer uso de un flujo mayor de información que incide sobre nuestra capacidad interpretativa de una escena $\mathrm{y}$, por tanto, sobre la consideración de su grado de cordialidad. En este sentido, tanto las consignas como los elementos no verbales y el mismo entorno (colores, sonidos, música ambiental, etc.) infieren en la respuesta.

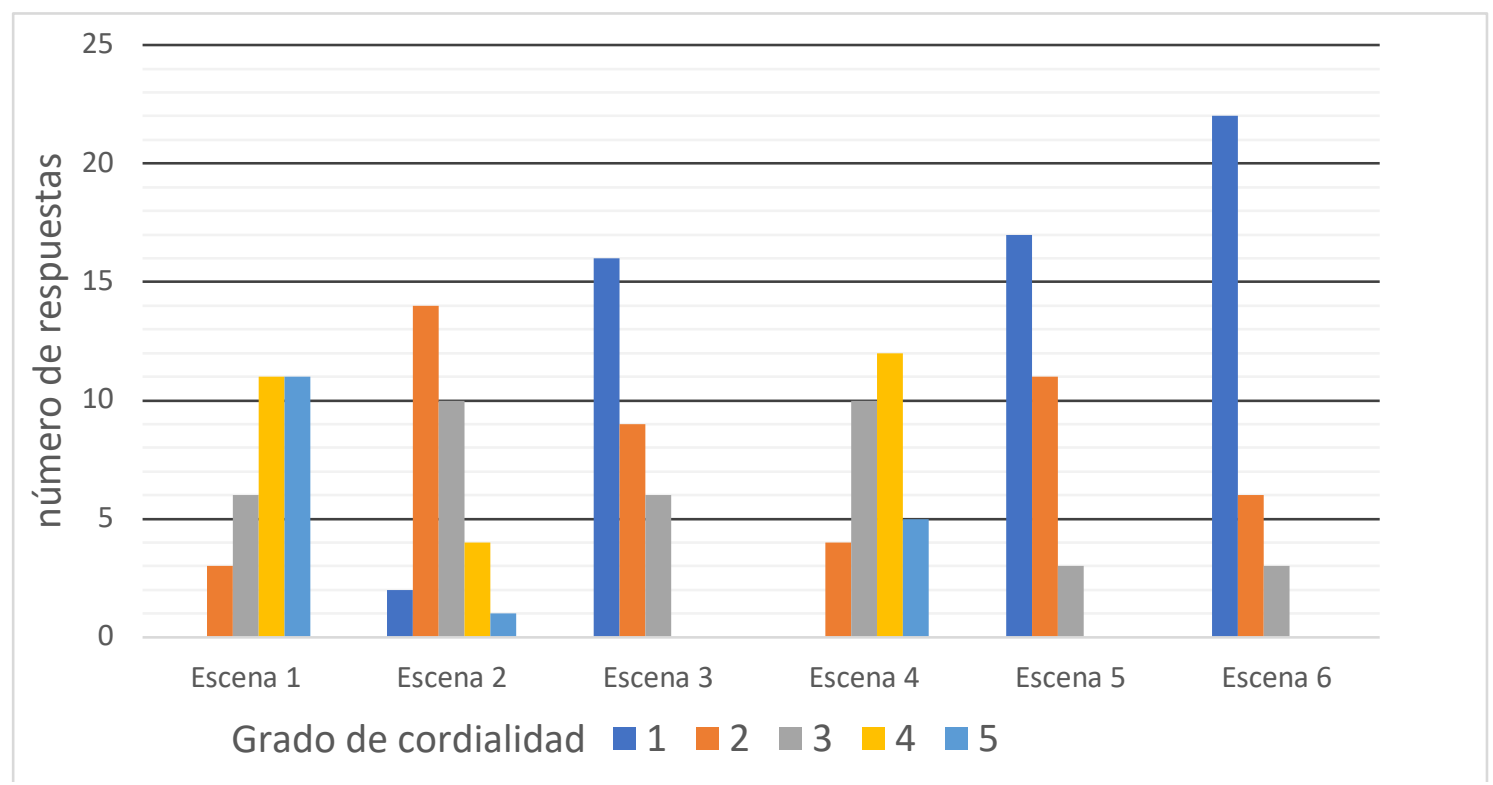

Imagen 2. Relación escena-cordialidad.

Por ello, podemos observar cómo el grado de cordialidad de las escenas 1, 2 y 4 es interpretado de manera heterogénea. Por el contrario, las escenas 3, 5 y 6 son interpretadas como no cordiales y presentan un grado de variabilidad menor, razón por la que cabe esperar, 
de oficio, que las estrategias comunicativas desarrolladas y los procedimientos incluidos tenderán a ser más homogéneos.

\section{Pregunta 1: PETICIÓN (54" - 59"). El niño pide una casita de madera para su monstruito. ¿Cómo lo dirías si fueras el niño?}

El nivel de cordialidad de la primera escena ha sido valorado, por lo general, como medioalto, para 28 de la totalidad de encuestados, es decir, para un 90\%. Las estrategias observadas entre las cuales podemos resaltar las siguientes:

1. Procedimiento directo: uso de secuencias enunciativas de carácter volitivo con el objetivo de conseguir un determinado fin:

- «Quiero esa casita.»

- «Querría una casita para mi amigo.»

- «Hola, quiero esa casita de madera para mi amigo el monstruito.»

- «¿Me das esa casita para mi amigo?», «¿Puedo tener esa casita para mi mascota?»

2. A medida que el nivel de cordialidad aumenta, se observa el uso de procedimientos indirectos, sobre todo a partir del nivel 4 o 5 . Los encuestados fueron optando por el uso de diversos tipos de estrategias atenuadoras. De todas ellas, destacamos:

- El uso recurrente del marcador discursivo «por favor».

- La interrogación directa o el uso de expresiones con verbos u oraciones condicionales: «¿Podría darme esa casita, por favor?», «Hola, señor. Yo...querría una de esas para mi amiguito, por favor», etc.

3. El uso de diminutivos ha sido muy reiterado en estos primeros casos, independientemente del nivel de cordialidad asignado a la escena. En este sentido, es probable que los encuestados hayan deseado ponerse en la piel del niño para imitar el uso de un lenguaje infantil. Podemos citar los siguientes elementos discursivos: casita, amiguito, monstruito.

Pregunta 2: RECHAZO (59" - 1'08"). El hombre, ante la petición del niño de tener una casita, mira el monstruo y le dice que no puede vendérsela porque debe ser un pájaro como el que ve. ¿Qué dirías en toda esta sección, si fueras el hombre?

Los niveles de cordialidad identificados para esta escena han sido muy variables. Es probable que parte de esa variabilidad se deba a la efusividad mostrada por el hombre mayor al negarse a vender la casita para pájaros, una efusividad contrastada con la reacción amigable del niño, a quien el rechazo no parece afectarle. Por todo ello, las estrategias y los procedimientos adoptados por los encuestados muestran principalmente una estructura binomial, compuesta por un acto principal (el rechazo, más abajo, en cursiva), acompañado o complementado por elementos periféricos (subactos). Algunos ejemplos pueden ser:

- «No puede ser, mis casas son solo para pájaros.»

- «No, no, chico. Esta casita solo es para pájaros como este.»

- «No, chico. O un pájaro o nada».

- «No puede ser chiquitín. Es una casita para pájaros como este.»

- «Lo siento pequeño, pero no te la puedo vender ya que tu mascota no es un pájaro.»

Se aprecia, por otra parte, una relación directa entre el uso de apelativos cariñosos como soporte a la unidad de habla concernida, y a la vez como marcador de contacto. En la inmensa 
mayoría de los casos, el marcador se encuentra en la parte final de la unidad de habla. Algunos ejemplos:

$$
\begin{aligned}
& \text { - chico } \\
& \text { - (mi) niño } \\
& \text { - jovencito } \\
& \text { - chiquitín }
\end{aligned}
$$

Resalta, asimismo, la aparente relación directa entre el grado de cordialidad indicado en cada acto de habla por los encuestados y el uso de atenuadores de cortesía, que pueden igualmente ir unidos a los apelativos cariñosos ya descritos. Para los siguientes casos (con un grado de cortesía elevado), la estructura del acto de habla se desarrolla, lo que genera soluciones más complejas, y a las que se unen, además, deícticos, repeticiones, marcadores discursivos y fórmulas fijas muy diversas:

- «Veamos... mmm, no, no puede ser. Mis casitas solo sirven para pájaros, ¿ves?»

- «Lo siento mucho, pequeño, pero tu mascota no es un pájaro. Estas casitas no son las mejores para él.»

- «Lo siento pequeño, pero no te la puedo vender ya que tu mascota no es un pájaro.»

Pregunta 3: MANDATO (1'38" - 1'46"). El pájaro, con cierto desdén, le espeta al monstruito que se aleje para enseñarle cómo entrar en la casita. ¿Cómo lo dirías si fueras el pájaro?

El desdén apreciado en esta escena, la brevedad de la misma, y la descripción del mismo enunciado, creemos, han sido claves para que la gran mayoría de los encuestados considerasen que el nivel de cordialidad de la situación comunicativa fuera bajo o muy bajo (nivel 1 o 2, principalmente). Resalta la simplicidad de determinadas expresiones, que evitan el uso de conectores o proposiciones complejas:

- «Quita.»

- «Apártate.»

- «iQuita del medio!»

De manera muy ligada a esa descortesía se evidencia el tuteo como estrategia de aproximación (o menosprecio) hacia el destinatario, así como el uso de apelativos descalificativos (por ejemplo, bicho, memo, impostor, ignorante) principalmente vinculados a un grado de cordialidad igual o inferior a 2.

El uso de «que» como elemento de inicio argumentativo queda reflejado en varias ocasiones, pudiendo ir acompañado de otro conector pragmático (por ejemplo, «anda»), confirmando así su recurrencia en el lenguaje coloquial:

- «Quita anda, que se abre así.»

- «iQuita memo que no sabes!»

- «Anda, quita, que no sabes cómo va esto.»

- «iAnda, quita, que tú no sabes!» 
Pregunta 4: INSTRUCCIÓN (2'41" - 2'50'). El hombre, al ver el niño con la regadera, le dice que no la debe utilizar para regar las plantas, sino que debe hacerlo con un pulverizador. ¿Cómo lo dirías si fueras el hombre?

Las respuestas vinculadas a esta escena dan cuenta de un enunciado compuesto, principalmente, por dos unidades pragmáticas: la exhortación (subacto) y la instrucción (acto principal). La sonrisa apreciada en el hombre mayor deja entrever un grado de cordialidad final medio-alto, lo que podría justificar que más del $87 \%$ de los encuestados (27 respuestas) hayan interpretado un nivel equivalente o superior a 3.

Las expresiones utilizadas son especialmente más complejas a medida que el grado de cordialidad aumenta, sobre todo a partir del nivel 4. Las expresiones para un nivel de cordialidad menor son más concretas, evitando elementos lingüísticos elaborados (proposiciones, argumentaciones) y apoyándose en el contexto y en los elementos cinésicos para conseguir una interpretación correcta de las unidades de habla:

Ejemplos extraídos de niveles de cordialidad inferiores a 4:

- «No, mejor mira...»

- «iQuieto! Con el pulverizador hombre, así.»

- «¡Niño, así no! ¡Con el pulverizador! ¡Así!»

Ejemplos extraídos de niveles de cordialidad iguales o superiores a 4 :

- «No, espera. Esta planta no se riega así, es malo para ella. Hay que pulverizar el agua con el spray, ¿lo ves?»

- «Para evitar que las plantas tengan demasiada agua que beber, es mejor que utilices este aparato que ves aquí. Así, solo les darás el agua que necesitan.»

- «No, no. Tienes que usar esto, que es mejor para ellas. ¿Ves? Así.»

Las respuestas también evidencian el uso reiterado de dos verbos clave en el acto «instrucción»: «mirar»y «ver». Mientras que el primero suele ser conjugado en modo imperativo, usualmente al principio o al final de la oración propuesta («[...], mira.»), el segundo suele aparecer en tiempo presente del indicativo en una oración interrogativa («ives?»).

- «No, mejor mira...»

- «No, chiquitín, mira, mejor así.»

- «Un momento pequeñito, no se usa la regadera para regar las plantas sino un pulverizador. ¡Mira!»

- «No, espera. Esta planta no se riega así, es malo para ella. Hay que pulverizar el agua con el spray, ¿lo ves?»

- «¡No!, ¡con la regadera no! Mira, se usa un pulverizador, ¿ves? Así, suavecito...»

- «No, no. Tienes que usar esto, que es mejor para ellas. ¿Ves? Así.»

Pregunta 5: QUEJA (3'46" - 3'57'). El hombre, al ver que el gran monstruo ha roto la maceta, se enoja y reclama al mismo que tenga cuidado. ¿Qué dirías si estuvieras en su lugar?

El carácter agresivo de la escena y la expresividad del hombre mayor lleva a gran parte de los encuestados a recurrir al disfemismo para expresar sus ideas y voluntades. El grado de cordialidad indicado en esta escena se sitúa principalmente en los niveles 1 y 2. 
Las estrategias propuestas por los encuestados son muy heterogéneas. Podemos, no obstante, identificar algunos elementos combinados entre sí:

- Expresiones de desaprobación que muestran el asombro por parte del hombre mayor al observar los efectos del descuido generados por el monstruo.

$\circ$ «Mira lo que...»

○ «¿Qué estás haciendo?»

○ «¿Pero qué carajo haces?»

- Marcadores ya gramaticalizados, términos interdictos que imprimen más fuerza a lo que se va a decir o a lo que se ha dicho: me cago en la leche, mira que [...], carajo, pero bueno, joder, etc.

- Descalificativos: bicho peludo, patoso

- La combinación de dos o más unidades pragmáticas, llegando a formar enunciados complejos en los que pueden conjugar marcadores de contacto, unidades difemísticas, conectores pragmáticos, secuencias argumentativas 0 conclusivas:

○ «¡Eh, tú! ¡Fuera! ¡Te has cargado la maceta!»

○ «Pero ¡Hombre!! ¡Ten cuidado! ¡Quita, quita y déjame barrer!»

○ «Mira que eres patoso ¡quita de en medio, bicho peludo!»

- «iMira lo que acabas de hacer! ¡Ten más cuidado, so trasto!»

Estos elementos (o parte de los mismos), como se puede observar, permiten diferentes combinaciones entre sí, dependiendo de la fuerza ilocutiva que el interlocutor desee transmitir y del efecto perlocutivo esperado de su discurso. De igual modo, nuevamente, se evidencia el carácter esquemático de las unidades de habla cuando el nivel de cordialidad identificado por los encuestados es bajo. Algunas expresiones pueden ser las siguientes:

- «Fuera, fuera, fuera, iya está bien!»

- «¡Cuidado! ¡Fuera de aquí!»

- «iCuidado, hombre!»

- «Pero, ¡hombre! ¡Ten cuidado!? ¡Te has cargado la maceta!»

- «¡Oye, tú, ten más cuidado!»

Pregunta 6: MANDATO (3'46" - 3'57'). El hombre, al ver que el gran monstruo ha roto la maceta, se enoja y reclama al mismo que tenga cuidado. ¿Qué dirías si estuvieras en su lugar?

Para terminar, la fuerza ilocutiva de la última escena es la del mandato, en un contexto de cordialidad muy bajo o nulo. No en vano, la inmensa mayoría de los encuestados (el $87 \%$ ) asocia la escena con un nivel igualo o inferior a 2. Las estrategias y procedimientos observados en este contexto parecen obedecer a reglas similares a las correspondientes al escenario anterior (pregunta 5):

- Expresiones de asombro y desaprobación (subacto: queja): «iMis pobres plantas!», «iMi bonsái!», «Noooooo...», «¡Esto es el colmo!»

- La unión de varias unidades pragmáticas en un mismo enuncio. En estos casos, resalta el acto principal «mandato» con el objeto de expulsar a los personajes del herbolario: «¡Fuera (de aquí)!», «iLargo!», «¡Todos fuera de aquí!», «iLargaos todos de una vez!», «iIros a la mierda!»

- Descalificativos y elementos difemísticos: «malditos bichos», «putos bichos», «i Iros a la mierda!» 
Por otra parte, cabe resaltar el uso de deícticos temporales y espaciales como intensificadores, en tanto que marcan la voluntad del interlocutor de que los destinatarios reaccionen inmediatamente ante el mandato.

- «Venga, fuera de aquí todos, ¡AHORA!»

- « ¡Todos fuera de aquí!»

- «Fuera de aquí todos YA.»

- «Fuera de aquí ahora mismo.»

\section{Conclusiones}

En este trabajo, nos hemos propuesto ahondar en el estudio de la cortesía como estrategia comunicativa, entendida como proceso de activación de recursos lingüísticos para asegurar un comportamiento adecuado de los miembros de una comunidad, sujeta a normas específicas de comportamiento socioculturales. Para ello, solicitamos a alumnos de Traducción e Interpretación que completaran, a distancia, un TCD sobre un soporte audiovisual. Los resultados indican una interpretación personal del grado de cordialidad para cada escena y situación comunicativa, no solamente a partir de la descripción de cada escena, sino a través del análisis personal que cada alumno realiza de todo el input recibido durante la tarea (colores del cortometraje, expresiones faciales, elementos cinésicos, trama global del cortometraje, etc.). En este sentido, la interpretación del contexto determina las estrategias y los procedimientos adoptados para cada situación.

De las seis escenas seleccionadas del cortometraje, dos fueron claramente identificadas con un alto grado de cordialidad por la mayoría de los encuestados: la primera (acto de habla: petición) y la cuarta (instrucción). En ambas escenas, las propuestas dadas coinciden en la elección de construcciones sintácticas y en la concatenación de subactos pragmáticos, acompañados de elementos atenuadores, haciendo que buena parte de las respuestas de los encuestados sean largas y argumentadas. Se observaron oraciones enunciativas o interrogativas condicionales, procedimientos indirectos, atenuadores de cortesía, marcadores discursivos o diminutivos, entre otros. Parece, por tanto, justificado establecer un grado de relación positiva entre el uso de expresiones complejas por parte de los participantes en la encuesta y el mayor grado de cordialidad interpretado en una determinada escena.

Por el contrario, las escenas tres (mandato), cinco (queja) y seis (mandato) han sido consideradas como poco o muy poco cordiales por la mayor parte de los encuestados. En ellas, destaca el empleo de expresiones de desaprobación, llegando al uso de disfemismos, descalificativos o intensificadores que, al combinarse entre sí, aumentan la fuerza ilocutiva del emisor y provocan ese bajo nivel de cordialidad referenciado. En contraposición con las escenas identificadas como más cordiales, las unidades de habla propuestas para estas tres resultan ser más esquemáticas, dando lugar a oraciones menos extensas y sintácticamente más simples.

Con respecto a la segunda escena (rechazo) se observa una mayor disparidad de opiniones en cuanto al grado de cordialidad. Así, las estrategias empleadas por quienes la identificaron como una escena cordial se corresponden con las empleadas en la primera y cuarta escena (nivel de cordialidad alto), pues tienden al uso de atenuadores de cortesía y oraciones complejas. Por su parte, los encuestados que consideraron la segunda escena como poco cordial se decantaron por estructuras binomiales, en las que al acto principal (generalmente el 
rechazo), cerrado en muchos casos mediante un marcador de contacto, le acompaña un subacto.

Por tanto, en línea con los trabajos indicados (Briz, 2017; Kerbrat-Orecchioni, 2004), el uso de conectores pragmáticos ha sido recurrente, ya sea como atenuadores o como intensificadores para conseguir la intención (cortés o no) del interlocutor. Otros elementos observados en este primer trabajo son el uso de fórmulas de cortesía de antiguo repertorio, elementos modalizadores o minimizadores, los intensificadores / atenuantes morfológicos, sintácticos, los deícticos, los lexemas marcados semánticamente, el uso de tiempos verbales concretos y la preferencia de determinadas unidades léxicas.

Por último, cabe reiterar la implicación que tienen, en este estudio, las convenciones socioculturales que determinan el uso de elementos de cortesía, así como la manera con la que las estrategias expresivas se materializan por parte de los nativos de español (variedad peninsular). La actividad aquí propuesta podría ser replicada en clase de ELE y, posteriormente, comparada con los datos aquí ofrecidos. También, los docentes podrían apoyarse en los ejemplos auténticos (a pesar del carácter prototípico de las expresiones, como consecuencia de la misma metodología empleada) para desarrollarlos por niveles de cordialidad. Por otra parte, el mismo análisis de este material podría ofrecer información de utilidad a alumnos no nativos, sobre el uso de normas pragmalingüísticas del español peninsular, reduciendo, de esa forma, la probabilidad de que los estudiantes de una L2 transfieran a la cultura española (C2) las estrategias discursivas utilizadas en su cultura $\mathrm{C} 1$.

\section{Bibliografía}

Albelda MARCO, M. (2004). «Cortesía en diferentes situaciones comunicativas. La conversación coloquial y la entrevista sociológica semiformal». En D. Bravo y A. Briz. (ed.), Pragmática Sociocultural: estudios sobre el discurso de cortesía en español (pp. 109-134). Barcelona: Ariel Letras.

Alvira MARTÍN, F. (2011). La encuesta: una perspectiva general metodológica. $2^{\text {a }}$ edición revisada. Madrid: Centro de Investigaciones Sociológicas (CIS).

BRAVO, D. (1999). «¿Imagen positiva vs. Imagen negativa?: pragmática sociocultural y componentes de face», Oralia: Análisis del discurso oral, 2, pp. 155-184.

BRAVO, D. (2004). «Tensión entre universalidad y relatividad en las teorías de la cortesía». En D. Bravo y A. Briz. (ed.), Pragmática Sociocultural: estudios sobre el discurso de cortesía en español (pp. 15-38). Barcelona: Ariel Letras.

BRIZ, A. (2017). El español coloquial: Situación y uso. $7^{\mathrm{a}}$ edición. Madrid: Arco Libros.

BRIZ, A. (2004). «Cortesía verbal codificada y cortesía verbal interpretada en la conversación». En D. Bravo y A. Briz. (ed.), Pragmática Sociocultural: estudios sobre el discurso de cortesía en español (pp. 67-94). Barcelona: Ariel Letras.

Brown, P. y LeVInson, S. (1987). Politeness. Some Universals in Language Use. Cambridge: Cambridge University Press.

CoHEN, A. (1998). «Developing pragmatic ability: A case study». En E. Castillo (ed.); Applied linguistics: Focus on second language learning/teaching (pp. 1-13). Manila: De La Salle University Press.

ESCANDELl VIDAL, Mª V. (2013). Introducción a la pragmática. Barcelona: Ariel. 
GALINDO MERINO, M M M. (2005). «La transferencia pragmática en el aprendizaje de ELE». En A. Álvarez et al. (ed.), La competencia pragmática y la enseñanza del español como lengua extranjera; actas del XVI Congreso Internacional de ASELE, Oviedo, 22-25 de septiembre de 2005 (pp. 289-297). Oviedo: Ediciones de la Universidad de Oviedo, Servicio de Publicaciones.

Goffman, E. (1967). Interaction Ritual: Essays on Face-to-Face Behaviour. New York: Doubleday.

Grice, H. P. (1975). «Logic and conversation». En P. Cole y J. L. Morgan (ed.), Syntax and Semantic. Speech Acts (pp. 41-58). Nueva York: Academic Press.

GutiÉRreZ ORDÓÑEZ, S. (2015). De pragmática y semántica. 2a edición. Madrid: Arco Libros.

HAVERKATE, H. (1994). La cortesía verbal. Estudio pragmalingüistico. Madrid: Gredos.

HERNÁNDEZ FLORES, N. (2004). «La cortesía como la búsqueda del equilibrio de la imagen social». En D. Bravo y A. Briz. (ed.), Pragmática Sociocultural: estudios sobre el discurso de cortesía en español (pp. 95-108). Barcelona: Ariel Letras.

KASPER, G. (2006). «Speech acts in interaction», Pragmatics and Language Learning, 11, pp. 281-314.

Kerbrat-Orecchioni, C. (2004). «¿Es universal la cortesía?». En D. Bravo y A. Briz. (ed.), Pragmática Sociocultural: estudios sobre el discurso de cortesía en español (pp. 39-54). Barcelona: Ariel Letras.

LAKOFF, R. (1973). «The logic of politeness: Or, minding your p's and q's». En C. Corum, T. Cedric Smith-Stark, y A. Weiser (ed.), Papers from the 9th Regional Meeting of the Chicago Linguistic Society (pp. 292-305). Chicago: Chicago Linguistic Society.

LEECH, G. (1983). Principles of Pragmatics. Londres: Longman.

MuÑOZ, C. (2000). Segundas lenguas: adquisición en el aula. Barcelona: Ariel.

PELÁEZ TORRES, M. (2017). «Aproximación sociopragmática y pragmalingüística a la formulación de buenos deseos y felicitaciones en español», Pragmalingüistica, 25, pp. 467489.

SEARLE, J. R. (2017). Actos de habla. 9a edición. Madrid: Cátedra.

\section{Anexo I: tabla de resultados, organizada por escena y grado de cordialidad asignado}

\begin{tabular}{|c|r|c|c|c|c|}
\hline Escena 1 & & Escena 2 & & Escena 3 & \\
\hline Quiero esa casita. & 2 & $\begin{array}{l}\text { Es una casita para pájaros, no para } \\
\text { monstruos. }\end{array}$ & 1 & Aparta de ahí y mira. & 1 \\
\hline Quiero esa casita. & 2 & $\begin{array}{l}\text { No, no, chico. Esta casita solo es } \\
\text { para pájaros como este. }\end{array}$ & 1 & $\begin{array}{l}\text { Quita anda, que se abre } \\
\text { así. }\end{array}$ & 1 \\
\hline $\begin{array}{l}\text { iQuiero esa casita para mi } \\
\text { monstruito! }\end{array}$ & 2 & $\begin{array}{l}\text { No puede ser, mis casas son solo } \\
\text { para pájaros. }\end{array}$ & 2 & Apártate. & 1 \\
\hline $\begin{array}{l}\text { Hola, quiero esa casita de } \\
\text { madera. }\end{array}$ & 3 & $\begin{array}{l}\text { Lo siento mi niño, solo vendo } \\
\text { casitas para pájaros... }\end{array}$ & 2 & $\begin{array}{c}\text { Échate a un lado, } \\
\text { observa. }\end{array}$ & 1 \\
\hline $\begin{array}{l}\text { Quiero esa casita de } \\
\text { madera. }\end{array}$ & 3 & $\begin{array}{l}\text { Esa casita es para pájaros como } \\
\text { este. }\end{array}$ & 2 & $\begin{array}{c}\text { Fuera. Lárgate de mi } \\
\text { casita. }\end{array}$ & 1 \\
\hline
\end{tabular}




\begin{tabular}{|c|c|c|c|c|c|}
\hline Quiero una. & 3 & $\begin{array}{l}\text { Esa CASITA es para pájaros. iiiTu } \\
\text { amiguito no es un PÁJARO!!! }\end{array}$ & 2 & ¡Quita! & 1 \\
\hline $\begin{array}{l}\text { Quiero una casita para mi } \\
\text { amigo. }\end{array}$ & 3 & $\begin{array}{l}\text { Es una casa para pájaros, no vale } \\
\text { para tu mascota. }\end{array}$ & 2 & ¡Quita! & 1 \\
\hline $\begin{array}{l}\text { ¿Quiero esa casita, por } \\
\text { favor! }\end{array}$ & 3 & $\begin{array}{l}\text { No, lo siento. No es un pájaro para } \\
\text { esa casita. }\end{array}$ & 2 & $\begin{array}{l}\text { ¡Quita, memo, que no } \\
\text { sabes! }\end{array}$ & 1 \\
\hline $\begin{array}{l}\text { ¿Puedo ver esa casita, por } \\
\text { fa? }\end{array}$ & 3 & No, chico. O un pájaro o nada. & 2 & ¡Aparta, impostor! & 1 \\
\hline $\begin{array}{l}\text { Mi monstruito necesita } \\
\text { una casita. ¿Tú podrías } \\
\text { ayudarme? }\end{array}$ & 4 & $\begin{array}{l}\text { Imposible jovencito, es para } \\
\text { pájaros, no para bichos. }\end{array}$ & 2 & Quita. & 1 \\
\hline $\begin{array}{l}\text { Hola señor, ¿puedo } \\
\text { comprar esa casita de } \\
\text { manera para mi amigo, por } \\
\text { favor? }\end{array}$ & 4 & $\begin{array}{l}\text { No, no, no... no es posible. Esas } \\
\text { casitas son para pájaros de verdad, } \\
\text { niña. }\end{array}$ & 2 & $\begin{array}{l}\text { Esta casa no es para } \\
\text { criaturas como tú. }\end{array}$ & 1 \\
\hline $\begin{array}{l}\text { ¿Me das esa casita para } \\
\text { mi amigo? }\end{array}$ & 4 & $\begin{array}{l}\text { Déjame ver a tu amigo.... mmm... } \\
\text { no, no puede ser. Ginés no es un } \\
\text { pájaro. Solo hago casas para pájaros. }\end{array}$ & 2 & $\begin{array}{l}\text { Anda, quita, que no } \\
\text { sabes cómo va esto. }\end{array}$ & 1 \\
\hline $\begin{array}{l}\text { Quería una casita para mi } \\
\text { mascota. }\end{array}$ & 4 & $\begin{array}{l}\text { La casita es para pájaros como este, } \\
\text { niño. }\end{array}$ & 2 & ¡Quita! & 1 \\
\hline ¡Quiero esa casita! & 4 & No, no. Es solo para pájaros. & 2 & $\begin{array}{l}\text { Aparta y deja que lo } \\
\text { haga yo. }\end{array}$ & 1 \\
\hline $\begin{array}{l}\text { Me gustaría una rasita } \\
\text { como esa para mi } \\
\text { monstruo, ipor fa! }\end{array}$ & 4 & $\begin{array}{l}\text { No puedo vendértela porque es } \\
\text { para animales como mi pájaro. }\end{array}$ & 2 & $\begin{array}{l}\text { Aléjate, que no sabes } \\
\text { abrirla. }\end{array}$ & 1 \\
\hline $\begin{array}{l}\text { Ginés necesita una casita } \\
\text { para vivir. ¿Podría usted } \\
\text { darme una como esa? }\end{array}$ & 4 & $\begin{array}{l}\text { No, esa casa es sólo para pájaros } \\
\text { como ese. }\end{array}$ & 2 & ¡Fuera! ¡La casa es mía! & 1 \\
\hline $\begin{array}{l}\text { ¿Quiero una de esas, por } \\
\text { favor! }\end{array}$ & 4 & $\begin{array}{l}\text { A ver... Ni hablar, es solo para } \\
\text { pájaros. }\end{array}$ & 3 & $\begin{array}{l}\text { ¡Discúlpame pequeñito! } \\
\text { ¡Déjame mostrarte como } \\
\text { se entra en esa casita! }\end{array}$ & 2 \\
\hline Quiero esa casita. & 4 & $\begin{array}{l}\text { Estas casitas son para pájaros como } \\
\text { este, no para bichos como el tuyo. }\end{array}$ & 3 & Quita! & 2 \\
\hline $\begin{array}{l}\text { ¿Podría darme esa casita, } \\
\text { por favor? }\end{array}$ & 4 & $\begin{array}{l}\text { ¿Para quién es? Oh, oh. No. Es } \\
\text { como para él. }\end{array}$ & 3 & $\begin{array}{l}\text { ¡Eh, tú! Aparta. Mira y } \\
\text { aprende. }\end{array}$ & 2 \\
\hline $\begin{array}{l}\text { Hola, quiero esa casita de } \\
\text { madera para mi amigo el } \\
\text { mostruito. }\end{array}$ & 4 & $\begin{array}{l}\text { No puede ser, chiquitín. Es una } \\
\text { casita para pájaros como este. }\end{array}$ & 3 & ¡Quita del medio! & 2 \\
\hline ¡Quiero esa! Esa mola... & 5 & $\begin{array}{l}\text { Imposible, las casitas que vendo } \\
\text { son solo para pajaritos. }\end{array}$ & 3 & ¡Quita bicho, aprende! & 2 \\
\hline ¡Mira allí, arriba! & 5 & $\begin{array}{l}\text { Veamos...mmm, no, no puede ser. } \\
\text { Mis casitas solo sirven para pájaros, } \\
\text { ¿ves? }\end{array}$ & 3 & $\begin{array}{l}\text { Quita de ahí, que yo sé } \\
\text { más sobre este tema. }\end{array}$ & 2 \\
\hline $\begin{array}{l}\text { ¡Dame esa, esa! ¡Quiero } \\
\text { esa! }\end{array}$ & 5 & $\begin{array}{l}\text { Ejem... ¿A ver? No puede ser. Esa } \\
\text { es una casita de pájaros. ¿Lo ves? }\end{array}$ & 3 & $\begin{array}{l}\text { ¡Eh, tú, quita! ¡Así se } \\
\text { hace! }\end{array}$ & 2 \\
\hline $\begin{array}{l}\text { Hola, señor. Yo... querría } \\
\text { una de esas para mi } \\
\text { amiguito, por favor. }\end{array}$ & 5 & $\begin{array}{l}\text { Déjame ver. No. Yo hago casas } \\
\text { para *pájaros*. }\end{array}$ & 3 & ¡¡Quita!!, ¡iquita!! & 2 \\
\hline Esa me gusta, señor & 5 & $\begin{array}{l}\text { No, no, Es una casa para pájaros } \\
\text { como este. }\end{array}$ & 3 & $\begin{array}{c}\text { A ver, aléjate y te } \\
\text { enseñaré como entrar }\end{array}$ & 3 \\
\hline $\begin{array}{l}\text { Quiero una casita para } \\
\text { pájaros, como esa. }\end{array}$ & 5 & $\begin{array}{l}\text { No puedes comprar esta casita. Es } \\
\text { para pájaros, no para monstruos. }\end{array}$ & 3 & $\begin{array}{l}\text { Quita, ignorante, no } \\
\text { tienes ni idea de cómo va } \\
\text { esto. }\end{array}$ & 3 \\
\hline $\begin{array}{l}\text { Hola, querría una casita } \\
\text { para mi mascota, por favor. }\end{array}$ & 5 & $\begin{array}{l}\text { Lo siento pequeño, pero no te la } \\
\text { puedo vender ya que tu mascota no } \\
\text { es un pájaro. }\end{array}$ & 4 & $\begin{array}{l}\text { ¡No, espera, quita!, así } \\
\text { no es... }\end{array}$ & 3 \\
\hline Señor, ¿tiene usted una & 5 & ¿A ver...? Lo siento, solo tenemos & 4 & ¡ Anda, quita, que tú no & 3 \\
\hline
\end{tabular}




\begin{tabular}{|l|r|l|l|l|l|}
\hline casita para mi mascota? & & casitas para pájaros. & sabes! & \\
\hline $\begin{array}{c}\text { ¿Puedo tener esa casita } \\
\text { para mi mascota? }\end{array}$ & 5 & $\begin{array}{l}\text { Lo siento mucho, pequeño, pero tu } \\
\text { mascota no es un pájaro. Estas } \\
\text { casitas no son las mejores para él. }\end{array}$ & $\begin{array}{c}\text { Anda quita que no } \\
\text { sabes, te voy a enseñar } \\
\text { cómo se hace. }\end{array}$ & 3 \\
\hline ¿Me da esa casita, porfa? & 5 & $\begin{array}{c}\text { A ver... iNo! La casa es para } \\
\text { pájaros como este... }\end{array}$ & 4 & iTú, quita! Se entra así. & 3 \\
\hline $\begin{array}{l}\text { Señor, ¿podría llevarme } \\
\text { esa casita para mi } \\
\text { monstruo? }\end{array}$ & 5 & $\begin{array}{c}\text { ¿A veer? ¡No!, esa casa son solo } \\
\text { para pájaros, ¿ves? como este. }\end{array}$ & 5 & Aparta de aquí. \\
\hline
\end{tabular}

\begin{tabular}{|c|c|c|c|c|c|}
\hline Sección 4 & & Sección 5 & & Sección 6 & \\
\hline No, mejor mira... & 2 & $\begin{array}{l}\text { Por favor, ten más } \\
\text { cuidado. }\end{array}$ & 1 & $\begin{array}{l}\text { ¡Mis pobres plantas! Fuera de aquí } \\
\text { ahora mismo. }\end{array}$ & 1 \\
\hline $\begin{array}{l}\text { No eso no, mejor utiliza el } \\
\text { pulverizador. }\end{array}$ & 2 & ¡Ten más cuidado! & 1 & ¡Fuera de mi tienda! Putos bichos. & 1 \\
\hline $\begin{array}{l}\text { ¡Niño, así no! ¡Con el } \\
\text { pulverizador! ¡Así! }\end{array}$ & 2 & $\begin{array}{l}\text { ¡Mira lo que has hecho! } \\
\text { ¡Apártate! }\end{array}$ & 1 & Fuera de aquí ahora mismo. & 1 \\
\hline $\begin{array}{l}\text { No hace falta la regadera, usa } \\
\text { esto mejor. }\end{array}$ & 2 & $\begin{array}{l}\text { ¿Te importaría tener más } \\
\text { cuidado? }\end{array}$ & 1 & ¡Fuera de aquí! ¡Y no volváis más! & 1 \\
\hline $\begin{array}{l}\text { Espera, con esa regadera no, } \\
\text { mejor con esto. }\end{array}$ & 3 & $\begin{array}{l}\text { ¿Qué estás haciendo? } \\
\text { ¿iNo ves que lo estáis } \\
\text { rompiendo todo!? }\end{array}$ & 1 & $\begin{array}{l}\text { ¡Esto es inadmisible! Fuera de aquí } \\
\text { todos YA. }\end{array}$ & 1 \\
\hline $\begin{array}{l}\text { ¿Quieto! Con el pulverizador, } \\
\text { hombre, así. }\end{array}$ & 3 & $\begin{array}{l}\text { ¡Eh, tú! ¡Fuera! ¡Me cago } \\
\text { en la leche! }\end{array}$ & 1 & $\begin{array}{l}\text { Fuera. Fuera de aquí. ¡Deja mis } \\
\text { plantas en paz! }\end{array}$ & 1 \\
\hline $\begin{array}{l}\text { Oh, no, eso no, necesitas un } \\
\text { pulverizador como este. }\end{array}$ & 3 & ¡Sal de aquí! & 1 & ¡Malditos bichos! ¡Fuera! & 1 \\
\hline $\begin{array}{l}\text { No, así no. Tienes que } \\
\text { emplear el vaporizador. }\end{array}$ & 3 & $\begin{array}{l}\text { ¡Pero qué carajo haces! } \\
\text { ¡Apártate! }\end{array}$ & 1 & ¡Iros a la mierda! & 1 \\
\hline $\begin{array}{l}\text { No. Uh, uh. Se hace así, } \\
\text { mira. ¿Ves? Despacio. }\end{array}$ & 3 & $\begin{array}{l}\text { Mira que eres patoso } \\
\text { iquita del medio, bicho } \\
\text { peludo! }\end{array}$ & 1 & $\begin{array}{l}\text { ¡Ala, se acabó! ¡Todo el mundo } \\
\text { fuera de aquí! }\end{array}$ & 1 \\
\hline No, no. Así, no. Se hace así. & 3 & $\begin{array}{ccc}\begin{array}{c}\text { ¡No! } \\
\text { ¡Atrás! }\end{array} & \text { ¡Estate } & \text { quieto! } \\
\end{array}$ & 1 & $\begin{array}{l}\text { ¡Te lo has comido! ¡Venga, largaos } \\
\text { de aquí! }\end{array}$ & 1 \\
\hline No, así, no. Con esto mejor. & 3 & $\begin{array}{l}\text { Eres igual que un elefante } \\
\text { en una cacharrería. Un } \\
\text { poquitín de cuidado, si tal. }\end{array}$ & 1 & $\begin{array}{l}\text { ¡iPero qué has hecho!! ¡Tú sabes el } \\
\text { tiempo que ha hecho falta para criar } \\
\text { esa planta? iiY te la comes como si } \\
\text { nada!! ¡iFuera de aquí ahora mismo!! }\end{array}$ & 1 \\
\hline $\begin{array}{l}\text { Así no, tienes que hacerlo } \\
\text { así, con este pulverizador. }\end{array}$ & 3 & No, no, no. Aparta, aparta. & 1 & $\begin{array}{l}\text { Os voy a dar a todos... ifuera de } \\
\text { mi vista! }\end{array}$ & 1 \\
\hline $\begin{array}{l}\text { No puedes usar la regadera, } \\
\text { podrías estropear mi planta. }\end{array}$ & 3 & $\begin{array}{l}\text { ¡Ten más cuidado! Has } \\
\text { roto la maceta. Quita, quita } \\
\text { de aquí que barra la que has } \\
\text { liado. }\end{array}$ & 1 & ¡No! ¡Fuera! ¡Fuera de aquí! & 1 \\
\hline $\begin{array}{l}\text { Ah... No, así no. Dale con el } \\
\text { pulverizador. }\end{array}$ & 3 & $\begin{array}{l}\text { Joder, iestás rompiendo } \\
\text { todo! Fuera de aquí. }\end{array}$ & 1 & ¡Se acabó! ¡Todo el mundo fuera! & 1 \\
\hline $\begin{array}{l}\text { Un momento, pequeñito, no } \\
\text { se usa la regadera para regar } \\
\text { las plantas sino un } \\
\text { pulverizador. ¡Mira! }\end{array}$ & 4 & $\begin{array}{l}\text { ¡Oye, tú! Tienes que tener } \\
\text { más cuidado con mis } \\
\text { plantas. }\end{array}$ & 1 & ¡Fuera de aquíííí!, ¡largo! & 1 \\
\hline $\begin{array}{l}\text { No, no, mira, tienes que } \\
\text { hacerlo así. }\end{array}$ & 4 & $\begin{array}{l}\text { Fuera de aquí, me ha } \\
\text { costado mucho que crezca. }\end{array}$ & 1 & ¡Fuera! ¡Largo de aquí! & 1 \\
\hline $\begin{array}{l}\text { Para que crezca alta y sana } \\
\text { debes usar el pulverizador. }\end{array}$ & 4 & $\begin{array}{l}\text { Fuera, fuera, fuera, iуa } \\
\text { está bien! }\end{array}$ & 1 & $\begin{array}{l}\text { ¡Mi bonsái! Nooooo... ¡Fuera, } \\
\text { fuera de aquí! ¡Y no volváis nunca } \\
\text { más, salvajes! }\end{array}$ & 1 \\
\hline Te mostraré cómo se hace & 4 & Me cago en todo. ¡Fuera & 2 & ¡Basta ya! ¡Fuera de aquí! & 1 \\
\hline
\end{tabular}




\begin{tabular}{|c|c|c|c|c|c|}
\hline $\begin{array}{l}\text { Las plantas se deben regar con } \\
\text { un pulverizador, así. }\end{array}$ & & de aquí! & & & \\
\hline $\begin{array}{l}\text { No, chiquitín, mira, mejor } \\
\text { así. }\end{array}$ & 4 & $\begin{array}{l}\text { Deberías irte de aquí. Eres } \\
\text { demasiado grande y rompes } \\
\text { todas mis macetas. }\end{array}$ & 2 & $\begin{array}{l}\text { ¡ißNoooo!!! iiimalditos!!! iiiifuera } \\
\text { de aquí!!!! ii¡largo!!! }\end{array}$ & 1 \\
\hline $\begin{array}{l}\text { No, espera. Esta planta no se } \\
\text { riega así, es malo para ella. } \\
\text { Hay que pulverizar el agua con } \\
\text { el spray, ¿lo ves? }\end{array}$ & 4 & ¡Anda con más cuidado! & 2 & $\begin{array}{l}\text { ¡Esto es el colmo! ¡Fuera todos los } \\
\text { bichos de mi tienda! }\end{array}$ & 1 \\
\hline No, no. Mira, se la riega así. & 4 & $\begin{array}{l}\text { ¡Ten cuidado! Has roto la } \\
\text { maceta. }\end{array}$ & 2 & $\begin{array}{l}\text { ¡Fuera todos! No quiero volver a } \\
\text { veros por aquí. }\end{array}$ & 1 \\
\hline $\begin{array}{l}\text { No, no, no. Así la vas a } \\
\text { ahogar. Mira. }\end{array}$ & 4 & ¡Fuera de aquí! & 2 & Fuera, fuera, fuera, ¡ya está bien! & 1 \\
\hline $\begin{array}{l}\text { No, así no se riega... mira, } \\
\text { con esto. }\end{array}$ & 4 & ¡Cuidado! !Fuera de aquí! & 2 & $\begin{array}{l}\text { ¡Fuera de aquí! ¡Mis plantas no se } \\
\text { comen! }\end{array}$ & 2 \\
\hline $\begin{array}{l}\text { Para evitar que las plantas } \\
\text { tengan demasiada agua que } \\
\text { beber, es mejor que utilices } \\
\text { este aparato que ves aquí. Así, } \\
\text { solo les darás el agua que } \\
\text { necesitan. }\end{array}$ & 4 & $\begin{array}{l}\text { ¡Mira lo que acabas de } \\
\text { hacer! ¡Ten más cuidado, so } \\
\text { trasto! }\end{array}$ & 2 & $\begin{array}{l}\text { ¡Se acabó! ¡Os quiero a todos fuera } \\
\text { de aquí! }\end{array}$ & 2 \\
\hline $\begin{array}{l}\text { ¡No! ¡con la regadera no! } \\
\text { Mira, se usa un pulverizador, } \\
\text { ¿ves? Así, suavecito... }\end{array}$ & 4 & $\begin{array}{c}\text { ¡Pero ten } \\
\text { hombre!, ¡fuera! }\end{array}$ & 2 & ¡Todos fuera de aquí! & 2 \\
\hline $\begin{array}{l}\text { No, no. Tienes que usar esto, } \\
\text { que es mejor para ellas. ¿Ves? } \\
\text { Así. }\end{array}$ & 4 & ¡Cuidado, hombre! & 2 & $\begin{array}{l}\text { ¡Eso es lo último que esperaba de } \\
\text { vosotros! ¡Fuera de mi tienda! }\end{array}$ & 2 \\
\hline $\begin{array}{l}\text { No. Mira cariño. No uses la } \\
\text { regadera. Se hace así. Con el } \\
\text { pulverizador. }\end{array}$ & 5 & $\begin{array}{l}\text { Pero bueno... iiiten } \\
\text { cuidado!!! iiiAparta!!! }\end{array}$ & 2 & ¡Todos fuera de aquí! & 2 \\
\hline Mejor con el pulverizador. & 5 & $\begin{array}{l}\text { ¡Eh, tú! ¡Fuera! ¡Te has } \\
\text { cargado la maceta! }\end{array}$ & 2 & $\begin{array}{l}\text { iiiVenga, fuera de aquí todos, } \\
\text { AHORA!!! }\end{array}$ & 2 \\
\hline $\begin{array}{l}\text { No, mira, así no. Tienes que } \\
\text { usar el pulverizador }\end{array}$ & 5 & $\begin{array}{l}\text { ¡Por favor! ¡Espera un } \\
\text { momento! ¡No entres más, } \\
\text { no hay demasiado espacio y } \\
\text { todo es muy frágil en la } \\
\text { tienda! }\end{array}$ & 3 & ¡Ya basta! & 3 \\
\hline $\begin{array}{l}\text { Espera. Te enseñaré cómo } \\
\text { regar esta planta. }\end{array}$ & 5 & \begin{tabular}{l}
\multicolumn{1}{|c}{ Pero ¡Hombre! ¡Ten } \\
cuidado! ¡Quita, quita y \\
déjame barrer!
\end{tabular} & 3 & $\begin{array}{l}\text { Pero ¿¿qué?? ¡¡Fuera!! ¡Largaos } \\
\text { todos de una vez! }\end{array}$ & 3 \\
\hline $\begin{array}{l}\text { No, no con eso no. Mira, con } \\
\text { esto es mejora para las plantas, } \\
\text { ¿ves? }\end{array}$ & 5 & ¡Oye, tú, ten más cuidado! & 3 & $\begin{array}{l}\text { ¡Todos fuera de aquí y no volváis } \\
\text { nunca! }\end{array}$ & 3 \\
\hline
\end{tabular}

